\title{
Implementation of a self-directed learning module for undergraduate medical students in biochemistry: sharing of an experience
}

Sir,

Self-directed learning SDL is a process where learners take the initiative for their own learning, become sensitive to personal learning needs, formulate the learning objectives, search for the resources and use them judiciously and finally evaluate the learning outcome. ${ }^{1}$

Self-directed learning has been recommended as a promising methodology for lifelong learning in medicine. Under the new Competency Based Medical Education curriculum, the Medical Council of India has made SDL mandatory in all subjects for teaching undergraduate medical students. In Biochemistry, 20 hours has been allotted for SDL out of total 280 hours of teaching allotted to the subject in $1^{\text {st }}$ phase MBBS.

SDL is one of the key components of adult learning as proposed by Malcolm Knowles. Mezirow et al, have correctly pointed out that "No concept is more central to what adult education is all about than SDL".

However, in spite of the widespread adoption of adult learning principles, reports on its utility or methods of implementation in undergraduate medical education are very limited. There is lack of evidence on the content that is most suitable for SDL and there are no uniform guidelines on how SDL can be implemented in teaching Biochemistry to undergraduate medical students.

Table 1: Steps of implementation of the SDL module.

\begin{tabular}{|c|c|}
\hline $\begin{array}{l}\text { Step } \\
\text { number }\end{array}$ & Component of the SDL module \\
\hline 1. & Sensitization of students and faculty regarding SDL \\
\hline 2. & $\begin{array}{l}\text { Planning the "challenge" to be given to the students so as to incorporate all the important points related to the } \\
\text { topic "Haeme degradation and Jaundice" }\end{array}$ \\
\hline 3. & $\begin{array}{l}\text { Making the pre-discussion questionnaire consisting of five MCQs related to the topic of SDL [*on Google } \\
\text { Forms] }\end{array}$ \\
\hline \multicolumn{2}{|c|}{ SESSION - 1: (conducted during the 1 hour SDL session slot in the timetable) } \\
\hline 4. & $\begin{array}{l}\text { Discussing the "challenge" (case) with the students and encouraging them to identify their learning needs and } \\
\text { learning resources (Case scenario attached as Appendix A) }\end{array}$ \\
\hline 5. & $\begin{array}{l}\text { Brainstorming by students in small groups of } 30 \text { each to formulate the learning objectives so as to bridge the } \\
\text { knowledge gap identified by them* } \\
\text { (*guided by the facilitators) (Learning Objectives attached as Appendix B) }\end{array}$ \\
\hline 6. & Sharing of the resource material by the facilitators \\
\hline 7. & Creating a Whatsapp group which includes all the students and facilitators \\
\hline 8. & $\begin{array}{l}\text { Utilizing the Whatsapp group to share additional resources and motivate students for doing self directed } \\
\text { learning* } \\
\text { (*During the gap of four days given to students for doing self study) }\end{array}$ \\
\hline 9. & Sharing the Google Forms link of the pre-discussion questionnaire with the students \\
\hline 10 . & Compilation of student responses to the pre-discussion questionnaire \\
\hline \multicolumn{2}{|c|}{ SESSION - 2: (conducted during the 2 hour tutorial slot in the timetable) } \\
\hline 11. & $\begin{array}{l}\text { Fish bowl method of small group teaching conducted on } 2 \text { consecutive days for batches A ( } 60 \text { students) and } \\
\text { B ( } 57 \text { students) respectively } \\
\text { (guided by the facilitators) }\end{array}$ \\
\hline 12. & Discussion and summarization by the facilitators \\
\hline 13. & Sharing the post-discussion questionnaire with the students \\
\hline 14. & Sharing the questionnaire for perception analysis with the students as well as the facilitators \\
\hline 15. & Compilation and analysis of student and facilitator responses \\
\hline
\end{tabular}


The concept of SDL thus remains elusive and students and educators find it difficult to define SDL. Moreover, there are difference in opinion regarding the worth of SDL in the undergraduate medical curriculum. ${ }^{3,4}$ Majority of the authors which have described SDL implementation, have found it very challenging and have stated that selection of appropriate topics is important.

Murad MH et al, had suggested that studies are needed to standardise the SDL module in medical undergraduate curriculum. ${ }^{5}$ The methods of evaluation also need to be standardised to determine the effectiveness of these components on learning outcome.

Authors wish to share our experience of SDL implementation on topic" Haeme degradation and Jaundice". The SDL module was conducted and implemented over two contact sessions of students and facilitators as outlined in Table 1.

The SDL session has shown a positive result in this study, prompting us to question why it should not be incorporated routinely in all subjects of undergraduate MBBS and why there is so much of apprehension among the faculty about when to implement, for what topic to implement and the perfect timing for its implementation during course of study? The apprehension among faculty members usually concerns the steps of implementing SDL correctly and effectively.

There are no hard and fast rules for implementation and authors need to innovate and utilize the resources available to us effectively. SDL is the teaching learning modality in which the primary purpose is to make students learn a topic through their own efforts with minimal guidance by the faculty/facilitators. The role of learner is the most crucial aspect in SDL because the learner has to take the initiative for his/her own learning, by formulating the learning objective, identifying appropriate learning resources and effectively utilizing these resources to learn the topic. Self directed learning is the first step to becoming lifelong learners and the success of an Indian Medical Graduate depends on this crucial role. Technology and medicine are rapidly advancing hand-in-hand and the doctors of the present and the future needs to constantly learn, unlearn and relearn to contribute effectively to meeting the healthcare needs of the society. Authors recommend that all departments of undergraduate MBBS begin implementing SDL sessions immediately and contribute to achieving the vision of the Medical Council of India.

Poonam Agrawal ${ }^{1}$, Niket Verma ${ }^{2 *}$

${ }^{1}$ Department of Biochemistry and Member, Medical Education Unit, Dr Baba Saheb Ambedkar Medical College, New Delhi, India

${ }^{2}$ Department of General Medicine and Member, Medical Education Unit, Army College of Medical Sciences, Delhi Cantt., New Delhi, India

*Correspondence:

Dr. Niket Verma, E-mail: drniketverma@gmail.com

\section{REFERENCES}

1. MS Knowles. Self-Directed Learning. A Guide for Learners and Teachers. (N.Y. Cambridge Books; 1975:18.

2. J. Mezirow. A Critical Theory of Self Directed Learning. New Directions for Continuing Education, N25 17-30;1985:17.

3. Hewitt-Taylor J. Teachers' and students' views on self-directed learning. Nurs Stand. 2002 Sep 1824;17(1):33-8. PubMed PMID: 12360738.

4. Fry H, Jones A. Self directed learning in the undergraduate dental curriculum.Br Dent J. 1995 Nov 25;179(10):373-6. PubMed PMID: 8519559.

5. Murad MH, Varkey P. Self-directed learning in health professions education. Ann Acad Med Singapore. 2008 Jul;37(7):580-90. Review. PubMed PMID: 18695772.

Cite this article as: Agrawal $\mathrm{P}$, Verma N.

Implementation of a self-directed learning module for undergraduate medical students in biochemistry: sharing of an experience. Int J Adv Med 2020;7:3613. 


\section{APPENDIX A - Case Scenario of SDL Module}

'A 40 year old male presented to the OPD with complaints of pain in the abdomen and yellowish discolouration of the skin and eyes for the past 7 days. The pain is mainly in the upper right region of the abdomen and is accompanied with loss of appetite, nausea andvomiting. He also tells the doctor that he is passing dark coloured urine and pale coloured stools for the past few days. General physical examination confirms icterus (jaundice). The attending physician wants to advise certain biochemical tests to confirm the diagnosis and the type of Jaundice'

\section{APPENDIX B - Specific Learning Objectives}

At the end of the SDL session, the $1^{\text {st }}$ phase student should be able to-

1. Define jaundice

2. Describe the biochemical pathways involved in bilirubin metabolism

3. Enumerate the types of jaundice

4. Describe the clinical presentation of the different types of jaundice

5. Enumerate and describe the biochemical tests used to diagnose jaundice

6. Discuss the basic steps in management of a patient with jaundice 